\title{
Analysis of Factors Affecting the Number of Infant and Maternal Mortality in East Java Using Geographically Weighted Bivariate Generalized Poisson Regression
}

\author{
Luh Eka Suryani and Purhadi \\ Department of Statistics, Faculty of Mathematics, Computing, and Data Science \\ Institut Teknologi Sepuluh Nopember \\ email: purhadi@statisitka.its.ac.id
}

\begin{abstract}
Poisson regression is a non-linear regression model with response variable in the form of count data that follows Poisson distribution. Modeling for a pair of count data that show high correlation can be analyzed by Poisson Bivariate Regression. Data the number of infant mortality and maternal mortality are count data that can be analyzed by Poisson Bivariate Regression. The Poisson regression assumption is an equidispersion where the mean and variance values are equal. However, the actual count data has a variance value which can be greater or less than the mean value (overdispersion and underdispersion). Violations of this assumption can be overcome by applying Generalized Poisson Regression. Characteristics of each regency can affect the number of cases occurred. This issue can be overcome by spatial analysis called Geographically Weighted Regression. This study analyzes the number of infant mortality and maternal mortality based on conditions in East Java in 2016 using Geographically Weighted Bivariate Generalized Poisson Regression (GWBGPR) method. Modeling is done with Adaptive Bisquare Kernel weighting which produces 3 regency groups based on infant mortality rate and 5 regency groups based on maternal mortality rate. Variables that significantly influence the number of infant and maternal mortality are the percentages of pregnant women visit health workers at least 4 times during pregnancy, pregnant women get Fe3 tablets, obstetric complication handled, clean household and healthy behavior, and married women with the first marriage age under 18 years.
\end{abstract}

Keywords-Adaptive Bisquare Kernel, GWBGPR, Infant Mortality, Maternal Mortality, Overdispersion

\section{INTRODUCTION}

$\mathrm{O}$ NE of important indicators in determining the level of public health in a region is infant mortality rate (IMR) and maternal mortality rate (MMR). Both variables are related. At the time of the baby in the womb, nutrients are obtained from their mother's body through the placenta. Therefore, the condition of their mother will affect both fetus and baby being born. In addition, when a new baby is born until the age of one year, the role of their mother is also very influential in the growth of the baby. Poisson regression is a non-linear regression that has equidispersion assumption where both mean and variance are equal. Both infant and maternal mortality rates are correlated count data with different variance and mean. Previous research has found that infant and maternal mortality have overdispersion and the value of Akaike Information Criterion (AIC) was high enough and caused the value of errors in the given model is large [1] [2]. A variance greater or less than the mean is called overdispersion and underdispersion which can be overcome by Generalized Poisson Regression.

Each regency in East Java has different characteristics because it is affected by geographical factor, cultural factor, etc. those characteristics may affect the number of case occurred which create data discrepancies in each region. The differences can be overcome by using spatial analysis named Geographically Weighted Regression. The AIC value of the Geographically Poisson Regression model is better than the Poisson regression model [3]. Previous research on the number of infant and maternal mortality in 2013 used Geographically Weighted Bivariate Generalized Poisson Regression method. The conclusion was 3 regency groups based on significant similarity on predictor variables in infant mortality cases and 1 regency group in maternal mortality cases [4].

In this study, we analyzed two response variables, which are the number of infant and maternal mortality in East Java in 2016. The analysis was done using Geographically Weighted Bivariate Poisson Regression method because the data was suspected to help in determining the factors that significantly affect to the number of infant and maternal mortality in East Java.

\section{II.LITERATURE}

\section{A. Poisson Regression}

The Poisson regression is a distribution for events that have a small probability, which the event depends on a certain time interval or in a particular region with observations using discrete variables and independent predictor variables. The Poisson distribution has the following probability model [5].

$$
f(y)=\left\{\begin{array}{c}
\frac{e^{-\lambda} \lambda^{y}}{y !}, y=0,1,2 \ldots ; \lambda>0 \\
0, \quad \text { otherwise }
\end{array}\right.
$$

Letting random variables $Y_{1}$ and $Y_{2}$ as $Y_{1}=X_{1}+X_{0}$ and $Y_{2}=X_{2}+X_{0}$. So, the random variables $Y_{1}$ and $Y_{2}$ are bivariate 
Poisson distribution with the probability function as in the equation

$$
f(y)=\left\{\begin{array}{c}
e^{-\left(\lambda_{0}+\lambda_{1}+\lambda_{2}\right)} \sum_{k=0}^{S} \frac{\lambda_{1}^{y_{1}-k} \lambda_{2}^{y_{2}-k} \lambda_{0}{ }^{k}}{\left(y_{1}-k\right) !\left(y_{2}-k\right) ! k !} ; \\
0 \quad y_{1}, y_{2}=0,1,2, \ldots ; \lambda_{0}, \lambda_{1}, \lambda_{2}>0 \\
; \quad \text { otherwise }
\end{array}\right.
$$

\section{B. Bivariate Generalized Poisson Regression (BGPR)}

Generalized Poisson Regression model is a suitable model used for data count where over / under dispersion occurs. So aside from there are $\lambda$ parameters is also there are $\alpha$ parameters as dispersion parameter. Bivariate Generalized Poisson Regression is the development of Bivariate Poisson Regression on data that has overdispersion or underdispersion case with the following

$$
\ln \left(\lambda_{i}\right)=\mathbf{x}_{i}^{\mathrm{T}} \boldsymbol{\beta}_{j}=\beta_{j 0}+\beta_{j 1} x_{1 i}+\beta_{j 2} x_{2 i}+\ldots+\beta_{j k} x_{k i}
$$

where,

$\mathbf{x}_{i}=\left[\begin{array}{llll}1 & x_{1 i} & \cdots & x_{k i}\end{array}\right]^{\mathrm{T}}$ and $\boldsymbol{\beta}_{j}=\left[\begin{array}{llll}\beta_{j 0} & \beta_{j 1} & \cdots & \beta_{j k}\end{array}\right]^{\mathrm{T}}$

Examination to determine whether the variables $\mathrm{Y}_{1}$ and $\mathrm{Y}_{2}$ follow the distribution of Bivariate Generalized Poisson, then Croxkett's test with the following hypothesis

$\mathrm{H}_{0}$ : The response variables $\mathrm{Y}_{1}$ and $\mathrm{Y}_{2}$ follow the Bivariate Generalized Poisson distribution

$\mathrm{H}_{1}$ : The response variables $\mathrm{Y}_{1}$ and $\mathrm{Y}_{2}$ do not follow the Bivariate Generalized Poisson distribution

Test statistics :

$$
T=\mathbf{Z}^{\mathbf{T}} \hat{\mathbf{V}}^{-\mathbf{1}} \mathbf{Z}
$$

where,

$\mathbf{Z}^{\mathbf{T}}=\left[\begin{array}{ll}Z_{Y_{1}} & Z_{Y_{2}}\end{array}\right] ; Z_{h}=\operatorname{var}\left[Y_{h}\right]-\bar{Y}_{h}, \quad h=1,2 \quad$ dan

$\hat{\mathbf{V}}=\frac{2}{n}\left[\begin{array}{ll}\hat{\lambda}_{1} & \hat{\lambda}_{12} \\ \hat{\lambda}_{12} & \hat{\lambda}_{2}\end{array}\right]$

$n=1,2 ; \quad \hat{\lambda}_{h}=\operatorname{vâr}\left(Y_{h}\right) ; \quad \hat{\lambda}_{g h}=\operatorname{côv}\left(Y_{g} Y_{h}\right), \mathrm{g}, h=1,2 ; g \neq h$

Reject $\mathrm{H}_{0}$ if $T>\chi^{2}{ }_{(n, \alpha)}$.

The Bivariate Generalized Poisson Regression model estimator is performed using Maximum Likelihood Estimation (MLE) method by maximizing likelihood function. The likelihood function of Bivariate Generalized Poisson is as follows

$$
\begin{aligned}
L(\boldsymbol{\theta})= & L\left(\lambda_{0}, \lambda_{1 i}, \lambda_{2 i}, \alpha_{1}, \alpha_{2}, \alpha_{0}\right) \\
= & \prod_{i=1}^{n} \lambda_{0} \lambda_{1 i} \lambda_{2 i} \exp \left(-\left(\lambda_{0}+\lambda_{1 i}+\lambda_{2 i}\right)-y_{1 i} \alpha_{1}-y_{2 i} \alpha_{2}\right) \\
& \sum_{k=0}^{\min \left(y_{1 i}, y_{2 i}\right)} \frac{\left(\lambda_{1 i}+\left(y_{1 i}-k\right) \alpha_{1}\right)^{y_{1 i}-k-1}}{\left(y_{1 i}-k\right) !} \frac{\left(\lambda_{2 i}+\left(y_{2 i}-k\right) \alpha_{2}\right)^{y_{2 i}-k-1}}{\left(y_{2 i}-k\right) !} \\
& \frac{\left(\lambda_{0}+k \alpha_{0}\right)^{k-1}}{k !}\left(e^{k \alpha_{1}+k \alpha_{2}-k \alpha_{0}}\right)
\end{aligned}
$$

Ln likelihood function obtained from the transformation of $\lambda_{j i}+\lambda_{0}=e^{\mathbf{x}_{i}^{\top} \beta_{j}}$ is as follows

$$
\begin{aligned}
\ln L(.)= & n \ln \lambda_{0}+\sum_{i=1}^{n} \ln \left(e^{\mathbf{x}^{\mathrm{T}} \boldsymbol{\beta}_{1}}-\lambda_{0}\right)+\sum_{i=1}^{n} \ln \left(e^{\mathbf{x}_{i}^{\mathrm{T}} \boldsymbol{\beta}_{2}}-\lambda_{0}\right)-n \lambda_{0}- \\
& \sum_{i=1}^{n}\left(e^{\mathbf{x}^{\mathrm{T}} \boldsymbol{\beta}_{1}}-\lambda_{0}\right)-\sum_{i=1}^{n}\left(e^{\mathbf{x}^{\mathrm{T}} \boldsymbol{\beta}_{2}}-\lambda_{0}\right)-\sum_{i=1}^{n} y_{1 i} \alpha_{1}-\sum_{i=1}^{n} y_{21 i} \alpha_{2}+\sum_{i=1}^{n} \ln W_{i}
\end{aligned}
$$

with,

$$
\begin{aligned}
W_{i}= & \sum_{k=0}^{\min \left(y_{1 i}, y_{2 i}\right)} \frac{\left(\left(e^{\mathbf{x}_{i} \beta_{1}}-\lambda_{0}\right)+\left(y_{1 i}-k\right) \alpha_{1}\right)^{y_{i i}-k-1}}{\left(y_{1 i}-k\right) !} \frac{\left(\left(e^{\mathbf{x}_{i}^{\mathrm{T}} \boldsymbol{\beta}_{2}}-\lambda_{0}\right)+\left(y_{2 i}-k\right) \alpha_{2}\right)^{z_{2 i}-k-1}}{\left(y_{2 i}-k\right) !} \\
& \frac{\left(\lambda_{0}+k \alpha_{0}\right)^{k-1}}{k !}\left(e^{k \alpha_{1}+k \alpha_{2}-k \alpha_{0}}\right)
\end{aligned}
$$

To obtain the parameter estimates of the BGPR model, the $\ln L($.) function is derived against each parameter and equated to zero. The equation can not be solved analytically, so the settlement uses the Newton-Raphson iteration.

$$
\hat{\boldsymbol{\theta}}_{(m+1)}=\hat{\boldsymbol{\theta}}_{(m)}-\mathbf{H}^{-1}\left(\hat{\boldsymbol{\theta}}_{(m)}\right) \boldsymbol{g}\left(\hat{\boldsymbol{\theta}}_{(m)}\right)
$$

The value of $\hat{\boldsymbol{\theta}}_{(m)}$ is the estimated value of the parameter during the iteration to $m, \mathbf{g}\left(\hat{\boldsymbol{\theta}}_{(m)}\right)$ is a gradient vector with $\hat{\boldsymbol{\theta}}_{(m)}$ as parameter, and $\mathbf{H}\left(\hat{\boldsymbol{\theta}}_{(m)}\right)$ is a Hessian matrix with $\hat{\boldsymbol{\theta}}_{(m)}$ parameters.

Preliminary estimates of alpha parameters use the Ordinary Least Square (OLS) method. Iteration will stop if the $\left\|\hat{\boldsymbol{\theta}}_{(m-1)}-\hat{\boldsymbol{\theta}}_{(m)}\right\|<\varepsilon$ and $\varepsilon>0$ values are very small.

Testing of Bivariate Generalized Poisson Regression model parameters is done by Maximum Likelihood Ratio Test (MLRT) method with hypothesis

$\mathrm{H}_{0}: \beta_{j 1}=\beta_{j 2}=\ldots=\beta_{j k}=0$ and $\alpha_{1}=\alpha_{2}=0$

$\mathrm{H}_{1}$ : there is at least one $\beta_{j k} \neq 0$ and $\alpha_{j} \neq 0 ; j=1,2 ; k=1,2, \ldots, 6$

Test statistics:

$D(\hat{\beta})=-2\left(\ln L_{1}(\hat{\omega})-\ln L_{1}(\hat{\Omega})\right)$

Reject $\mathrm{H}_{0}$ if $D(\hat{\beta})>\chi_{(a ; a-b)}^{2}$.

$a$ is the number of parameters below population and $b$ is the number of parameters below $\mathrm{H}_{0}$. If the test decision simultaneously is rejected $\mathrm{H}_{0}$ then the next step to do partial parameter testing to determine which parameters that give a significant influence on the model. The hypotheses are

1. $\beta$ parameter

$\mathrm{H}_{0}: \beta_{j k}=0$

$\mathrm{H}_{1}: \beta_{j k} \neq 0 ; j=1,2 ; k=1,2, \ldots, 6$

Test statistics:

$Z=\frac{\hat{\beta}_{j k}}{\operatorname{se}\left(\hat{\beta}_{j k}\right)}$

$\operatorname{se}\left(\hat{\beta}_{j k}\right)$ is a standard error from $\hat{\beta}_{j k}$. Reject $\mathrm{H}_{0}$ if $|Z|>Z_{(\alpha / 2)}$.

2. $\alpha$ parameter

$\mathrm{H}_{0}: \alpha_{j}=0$

$\mathrm{H}_{1}: \alpha_{j} \neq 0 ; j=1,2$

Test statistics:

$Z=\frac{\hat{\alpha}_{j}}{\operatorname{se}\left(\hat{\alpha}_{j}\right)}$

$s e\left(\hat{\alpha}_{j}\right)$ is a standard error from $\hat{\alpha}_{j}$. Reject $\mathrm{H}_{0}$ if $|Z|>Z_{(\alpha / 2)}$.

\section{C.Spatial Effects}

The modeling of spatial data can be grouped based on the spatial data type ie spatial point and spatial area. In spatial data modeling, it is possible variations in terms of the region called spatial heterogeneities which indicate differences in regional 
relationship. The hypothesis used to see if there is spatial heterogeneity were described as

$\mathrm{H}_{0}: \sum_{1}=\sum_{2}=\ldots=\sum_{n}=\sum$ (there is no spatial heterogeneity)

$\mathrm{H}_{1}$ : there is at least one $\sum_{n} \neq \sum$ (there is spatial heterogeneity)

Test statistics:

$$
G=-\left[n-k-1-\frac{1}{2}(j-k+1)\right] \ln \left(\frac{\left|\hat{\Sigma}_{\Omega}\right|}{\left|\hat{\Sigma}_{\omega}\right|}\right) \sim \chi_{(a, j k)}^{2}
$$

$\sum_{\omega}$ is a matrix of covariant variance below $\mathrm{H}_{0}$ and $\sum_{\Omega}$ is a matrix of covariant variance below population. Reject $\mathrm{H}_{0}$ if $|G|>\chi_{(a, j k)}^{2}[6]$.

Distant locations also show spatial diversity. Spatial diversity between location is indicated by a weighted $W$ matrix which is a function from Euclidian distance of locations. One alternative weighting function is Adaptive Bisquare Kernel function. The adaptive kernel function is a kernel function that has different bandwidth at each location [7].

$$
w_{i i^{*}}=\left\{\begin{array}{l}
\left(1-\left(\frac{d_{i i^{*}}}{h_{i}}\right)^{2}\right)^{2} ; d_{i i^{*}} \leq h_{i} \\
0 \quad ; d_{i i^{*}}>h_{i}
\end{array}\right.
$$

$d_{i i^{*}}=\sqrt{\left(u_{i}-u_{i^{*}}\right)^{2}+\left(v_{i}-v_{i^{*}}\right)^{2}} \cdot d_{i i^{*}}$ is the Euclidian distance between the $i$-location and the $i^{*}$-location whereas $h_{i}$ is the smoothing parameter or the bandwidth of the $i$-location. The Adaptive function will have different bandwidths according to the data density in the analysis area. When the data is solid, the bandwidth will be small, whereas when the data is sparse, the bandwidth will get bigger. This function is able to adjust the size of data variance [8]. The selection of the optimum bandwidth can be done by the Generalized Cross Validation (GCV) method defined by equation (13)

$$
\min \left\{n \sum_{i=1}^{n} \frac{\left[\mathbf{Y}_{i}-\hat{\mathbf{Y}}_{\neq i}(h)\right]^{\mathrm{T}} \mathbf{Y}_{i}-\hat{\mathbf{Y}}_{\neq i}(h)}{\left(n-v_{1}\right)^{2}}\right\}
$$

where,

$$
v_{1}=\operatorname{Tr}\left[\begin{array}{c}
\mathbf{X}_{1}\left(\mathbf{X}^{\mathrm{T}} \mathbf{W}\left(u_{1}, v_{1}\right) \mathbf{X}\right)^{-1} \mathbf{X}^{\mathrm{T}} \mathbf{W}\left(u_{1}, v_{1}\right) \\
\mathbf{X}_{1}\left(\mathbf{X}^{\mathrm{T}} \mathbf{W}\left(u_{2}, v_{2}\right) \mathbf{X}\right)^{-1} \mathbf{X}^{\mathrm{T}} \mathbf{W}\left(u_{2}, v_{2}\right) \\
\vdots \\
\mathbf{X}_{1}\left(\mathbf{X}^{\mathrm{T}} \mathbf{W}\left(u_{i}, v_{i}\right) \mathbf{X}\right)^{-1} \mathbf{X}^{\mathrm{T}} \mathbf{W}\left(u_{i}, v_{i}\right)
\end{array}\right]
$$

$\hat{\mathrm{Y}}_{\neq i}$ is estimator value $y_{i}$ when observation in $\left(u_{i}, v_{i}\right)$ location not included in the estimation.

\section{Geographically Weighted Bivariate Generalized Poisson Regression (GWBGPR)}

The GWBGPR model is an extension of the Bivariate Generalized Poisson regression (BGPR) by using geographical weighting in its parameter estimation. The form of GWBGPR equation is as follows

$$
\begin{aligned}
\ln \left(\lambda_{j k}\left(u_{i}, v_{i}\right)\right)= & \beta_{j 0}\left(u_{i}, v_{i}\right)+\beta_{j 1}\left(u_{i}, v_{i}\right) x_{1 i}+\beta_{j 2}\left(u_{i}, v_{i}\right) x_{2 i} \\
& +\ldots+\beta_{j k}\left(u_{i}, v_{i}\right) x_{k i}
\end{aligned}
$$

The Geographically Weighted Bivariate Generalized Poisson Regression (GWBGPR) parameter estimator is performed by using the Maximum Likelihood Estimation (MLE) method. MLE method maximizes likelihood function. GWBGPR parameter estimation methods use MLE and likelihood function are described as shown in Formula 15.

$$
\begin{gathered}
L\left(\lambda_{0}\left(u_{i}, v_{i}\right), \lambda_{1 i}\left(u_{i}, v_{i}\right), \lambda_{2 i}\left(u_{i}, v_{i}\right), \alpha_{1}\left(u_{i}, v_{i}\right), \alpha_{2}\left(u_{i}, v_{i}\right), \alpha_{0}\left(u_{i}, v_{i}\right)\right)=\prod_{i=1}^{n}\left[\lambda_{0}\left(u_{i}, v_{i}\right) \lambda_{1 i}\left(u_{i}, v_{i}\right) \lambda_{2 i}\left(u_{i}, v_{i}\right)\right. \\
\left.\quad \exp \left\{-\left(\lambda_{0}\left(u_{i}, v_{i}\right)+\lambda_{1 i}\left(u_{i}, v_{i}\right)+\lambda_{2 i}\left(u_{i}, v_{i}\right)\right)-y_{1 i} \alpha_{1}\left(u_{i}, v_{i}\right)-y_{2 i} \alpha_{2}\left(u_{i}, v_{i}\right)\right\}\right] \\
\sum_{k=0}^{\min \left(y_{11}, v_{21}\right)} \frac{\left(\lambda_{i i}\left(u_{i}, v_{i}\right)+\left(y_{1 i}-k\right) \alpha_{1}\left(u_{i}, v_{i}\right)\right)}{\left(y_{1 i}-k\right) !} \exp \left(k\left(\alpha_{1}\left(u_{i}, v_{i}\right)+\alpha_{2}\left(u_{i}, v_{i}\right)-\alpha_{0}\left(u_{i}, v_{i}\right)\right)\right) \\
\frac{\left(\lambda_{2 i}\left(u_{i}, v_{i}\right)+\left(y_{2 i}-k\right) \alpha_{2}\left(u_{i}, v_{i}\right)\right)^{y_{2}-k-1}}{\left(y_{2 i}-k\right) !} \frac{\left(\lambda_{0}\left(u_{i}, v_{i}\right)+k \alpha_{0}\left(u_{i}, v_{i}\right)\right)^{k-1}}{k !}
\end{gathered}
$$

GWBGPR model factor which considered as weighting is the geographical factor of each observation point. The ln likelihood function form with $\left(w_{i i *}\right)$ graphic weighted for each observation point is described as shown in Formula 16.

$Q^{*}=\ln L\left(\lambda_{0}\left(u_{i}, v_{i}\right), \lambda_{i i}\left(u_{i}, v_{i}\right), \lambda_{2 i}\left(u_{i}, v_{i}\right), \alpha_{1}\left(u_{i}, v_{i}\right), \alpha_{2}\left(u_{i}, v_{i}\right), \alpha_{0}\left(u_{i}, v_{i}\right)\right)$

$$
\begin{aligned}
& =\sum_{i=1}^{n} \ln \lambda_{0}\left(u_{i}, v_{i}\right)\left(w_{i^{*}}\right)+\sum_{i^{*}=1}^{n} \ln \left(e^{x^{\top} \cdot \beta_{1}\left(u_{i}, v_{i}\right)}-\lambda_{0}\left(u_{i}, v_{i}\right)\right)\left(w_{i^{*}}\right)+\sum_{i^{*}=1}^{n} \ln \left(e^{\left.x_{i}^{\top} \boldsymbol{T}_{2}, u_{i}, v_{i}\right)}-\lambda_{0}\left(u_{i}, v_{i}\right)\right)\left(w_{i^{*}}\right) \\
& -\sum_{i=1}^{n} \lambda_{0}\left(u_{i}, v_{i}\right)\left(w_{i^{*}}\right)-\sum_{i^{*}=1}^{n}\left(e^{\mathrm{x}_{1}^{\mathrm{T}} \boldsymbol{B}_{1}\left(u_{i}, v_{i}\right)}-\lambda_{0}\left(u_{i}, v_{i}\right)\right)\left(w_{i^{*}}\right)-\sum_{i^{*}=1}^{n}\left(e^{\mathrm{x}_{i}^{\mathrm{T}}, \beta_{2}\left(u_{i}, v_{i}\right)}-\lambda_{0}\left(u_{i}, v_{i}\right)\right)\left(w_{i^{*}}\right) \\
& -\sum_{i^{*}=1}^{n} \lambda_{i^{*}} \alpha_{1}\left(u_{i}, v_{i}\right)\left(w_{i^{*}}\right)-\sum_{i^{*}=1}^{n} \lambda_{i^{*}} \alpha_{2}\left(u_{i}, v_{i}\right)\left(w_{i^{*}}\right)+\sum_{i^{*}=1}^{n} \ln B_{i^{*}}\left(w_{i^{*}}\right)
\end{aligned}
$$

with,

$B_{i^{*}}=\sum_{k=0}^{\min \left(y_{1 i}, y_{2 i}\right)} B_{1 i^{*}} B_{2 i^{*}}$

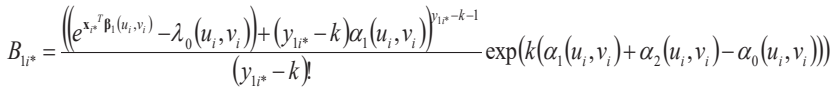

$B_{2 i^{*}}=\frac{\left(\left(e^{\mathbf{x}_{i}{ }^{T} \beta_{2}\left(u_{i}, v_{i}\right)}-\lambda_{0}\left(u_{i}, v_{i}\right)\right)+\left(y_{2 i^{*}}-k\right) \alpha_{2}\left(u_{i}, v_{i}\right)\right)^{z_{2 i^{*}-k-1}}}{\left(y_{2 i^{*}}-k\right) !} \frac{\left(\lambda_{0}\left(u_{i}, v_{i}\right)+k \alpha_{0}\left(u_{i}, v_{i}\right)\right)^{k-1}}{k !}$

At first, the derivative is not close form, so to obtain the GWBGPR estimator is done by using the Newton-Raphson iteration is described as shown in Formula 17.

$$
\hat{\boldsymbol{\theta}}\left(u_{i}, v_{i}\right)_{(m+1)}=\hat{\boldsymbol{\theta}}\left(u_{i}, v_{i}\right)_{(m)}-\mathbf{H}^{-1}\left(\hat{\boldsymbol{\theta}}\left(u_{i}, v_{i}\right)_{(m)}\right) \hat{\mathbf{g}}\left(\hat{\boldsymbol{\theta}}\left(u_{i}, v_{i}\right)_{(m)}\right)(17)
$$

Testing of Geographically Weighted Bivariate Generalized Poisson Regression model is used to know the significance of $\alpha$ and $\beta$ parameters together with the following hypothesis

$\mathrm{H}_{0}: \beta_{j 1}\left(u_{i}, v_{i}\right)=\beta_{j 2}\left(u_{i}, v_{i}\right)=\ldots=\beta_{j k}\left(u_{i}, v_{i}\right)$ and

$$
\alpha_{1}\left(u_{i}, v_{i}\right)=\alpha_{2}\left(u_{i}, v_{i}\right) ; i=1,2, \ldots, n
$$

$\mathrm{H}_{1}$ : there is at least one $\beta_{j k}\left(u_{i}, v_{i}\right) \neq 0$ and $\alpha_{j}\left(u_{i}, v_{i}\right) \neq 0$

Test statistics:

$D\left(\hat{\boldsymbol{\theta}}\left(u_{i}, v_{i}\right) i=1,2, \ldots, n\right)=\left(-2\left(\ln L_{1}(\hat{\omega})-\ln L_{1}(\hat{\Omega})\right)\left(u_{i}, v_{i}\right)\right)$

$D\left(\hat{\boldsymbol{\theta}}\left(u_{i}, v_{i}\right) ; i=1,2, \ldots, n\right)$ is the $\chi^{2}$ distribution approach with degrees of freedom (a-b), where $a$ is the number of parameters below population and $b$ is the number of parameters below $\mathrm{H}_{0}$. Reject $\mathrm{H}_{0}$ if $D\left(\hat{\boldsymbol{\theta}}\left(u_{i}, v_{i}\right) i=1,2, \ldots, n\right)>\chi_{(a ; a-b)}^{2}$ then there are predictor variables that affect the response variables with alpha is a significance level [4].

\section{E. Correlation}

The correlation coefficient is an indicator or a value in the linear relationship between two variables [9]. The correlation coefficient is defined as in (19)

$$
r_{y_{1}, y_{2}}=\frac{\sum_{i=1}^{n}\left(y_{1 i}-\bar{y}_{1}\right)\left(y_{2 i}-\bar{y}_{2}\right)}{\sqrt{\left(\sum_{i=1}^{n}\left(y_{1 i}-\bar{y}_{1}\right)^{2}\right)\left(\sum_{i=1}^{n}\left(y_{2 i}-\bar{y}_{2}\right)^{2}\right)}}
$$


The correlation coefficient can show two relationships, namely positive and negative. Correlation test for response variables is done with a hypothesis as follows

$\mathrm{H}_{0}$ : there is no relationship between $\mathrm{Y}_{1}$ and $\mathrm{Y}_{2}$

$\mathrm{H}_{1}$ : there is a relationship between $\mathrm{Y}_{1}$ and $\mathrm{Y}_{2}$

Test statistics:

$$
t=\frac{r_{y_{1}, y_{2}} \sqrt{n-2}}{\sqrt{1-\left(r_{y_{1}, y_{2}}\right)^{2}}}
$$

Reject $\mathrm{H}_{0}$ if $\left|t_{h i t}\right|>t_{(\alpha / 2 ;(n-2))}$

\section{F. Multicollinearity}

Multicollinearity is a condition in which predictor variables are highly correlated. The existence of a multicollinearity case may result in an inaccurate parameter estimate. The VIF value shows how the variance of the parameter estimation results of increases due to the presence of multicollinearity.

$$
V I F=\frac{1}{1-R_{k}^{2}}
$$

\section{G. Best Model Selection}

The use of many variables in multivariate regression analysis can be difficult to determine the effect of predictor variables on response variables. Therefore, the selection of variables is done to obtain the best regression model. Variable selection procedure with Mean Square Error (MSE) criterion. The best model has the smallest MSE value. MSE is the average of the squared estimation error were described as shown in Formula 21.

$$
M S E_{j}=\frac{\sum_{i=1}^{n}\left(y_{j i}-\hat{y}_{j i}\right)^{2}}{n} ; j=1,2
$$

AIC is the conformity criterion of the model in estimating the model statistically. AIC criteria are used when regression modeling aims to identify factors affecting the model. The selection of the best models from GWBGPR uses the AIC value [6].

$$
A I C=n \ln \left(\left|\hat{\Sigma}_{d}\right|\right)-2 J K
$$

where,

$\hat{\Sigma}_{d}=\frac{1}{n} \sum_{i=1}^{n} \hat{\varepsilon}_{i}^{\mathrm{T}} \hat{\varepsilon}_{i}$

$n=$ the number of observations

$J=$ the number of response variables

$K=$ the number of predictor variables

\section{H. Infant Mortality Rate and Maternal Mortality Rate}

Infant deaths are deaths occurring shortly after birth until the baby has not been exactly one year old. The causes of infant mortality are divided into two types namely endogenous and exogenous [10]. Maternal mortality is the death of a woman who occurs during pregnancy up to 42 days after the end of pregnancy, regardless of the length and place of pregnancy, but not due to an accident. Maternal mortality is categorized into direct death and indirect death [11].

\section{MethodOLOGY}

The data used in this study is secondary data obtained from the Central Statistics Agency of East Java and Health Profile of East Java 2016 issued by East Java Provincial Health Office. The observation unit of 38 observation units consisted of 29 districts and 9 cities. The study variables used in this study

\begin{tabular}{|c|c|}
\hline Variables & Details \\
\hline$Y_{1}$ & The number of infant mortality \\
\hline$Y_{2}$ & The number of maternal mortality \\
\hline$X_{1}$ & $\begin{array}{l}\text { Percentage of pregnant women visit health workers at } \\
\text { least } 4 \text { times during pregnancy }\end{array}$ \\
\hline$X_{2}$ & Percentage of pregnant women received $\mathrm{Fe} 3$ tablets \\
\hline$X_{3}$ & Percentage of obstetric complications handled \\
\hline$X_{4}$ & $\begin{array}{l}\text { The percentage of deliveries was helped by health } \\
\text { personnel }\end{array}$ \\
\hline$X_{5}$ & Percentage of households are living clean and healthy \\
\hline$X_{6}$ & $\begin{array}{l}\text { Percentage of married women with first marriage age } \\
\text { under } 18 \text { years of age }\end{array}$ \\
\hline
\end{tabular}
consisted of two response variables and five predictor variables. TABLE 1

RESEARCH VARIABLES

Source: Health Profile of East Java and Central Bureau of Statistics of East Java Year 2016 [12]

\section{EMPIRICAL RESULTS}

\section{A. Descriptive Statistics}

East Java is one of the most populous provinces in Indonesia. It is located $111.0^{\circ}$ and $114.4^{\circ}$ east longitude and between 7.12 ${ }^{\circ}$ and $8.48^{\circ}$ south latitude. East Java divided into 38 regencies with 29 districts and 9 cities. In the early stages of this research, descriptive statistics of variables that allegedly affect the number of infants and maternal mortality in East Java were

\begin{tabular}{|c|c|c|c|c|}
\hline Variables & Mean & Variance & Min & $\operatorname{Max}$ \\
\hline $\begin{array}{l}\text { The number of infant } \\
\text { mortality }\end{array}$ & 124.30 & 5749.28 & 9.00 & 276.00 \\
\hline $\begin{array}{l}\text { The number of maternal } \\
\text { mortality }\end{array}$ & 14.05 & 69.40 & 1.00 & 37.00 \\
\hline $\begin{array}{l}\text { Percentage of pregnant } \\
\text { women visit health } \\
\text { workers at least } 4 \text { times } \\
\text { during pregnancy }\end{array}$ & 89.17 & 24.27 & 78.90 & 98.50 \\
\hline $\begin{array}{l}\text { Percentage of pregnant } \\
\text { women received Fe3 } \\
\text { tablets }\end{array}$ & 88.23 & 31.82 & 79.84 & 109.02 \\
\hline $\begin{array}{l}\text { Percentage of obstetric } \\
\text { complications handled }\end{array}$ & 96.03 & 238.09 & 62.10 & 129.50 \\
\hline $\begin{array}{l}\text { The percentage of } \\
\text { deliveries was helped } \\
\text { by health personnel }\end{array}$ & 94.74 & 9.65 & 87.40 & 99.90 \\
\hline $\begin{array}{l}\text { Percentage of } \\
\text { households are living } \\
\text { clean and healthy }\end{array}$ & 49.64 & 218.41 & 19.40 & 75.10 \\
\hline $\begin{array}{l}\text { Percentage of married } \\
\text { women with first } \\
\text { marriage age under } 18 \\
\text { years of age }\end{array}$ & 20.36 & 109.35 & 5.210 & 50.20 \\
\hline
\end{tabular}
described as shown in Table 2.

TABLE 2

DESCRIPTIVE StATISTICS OF RESEARCH VARIABLES

Table 2 shows the variance of infant and maternal mortality in East Java in 2016 is greater than the mean. It indicates a neglect of the Poisson regression assumption. The average number of 
infant mortality in every region is 124.3 incidents. The region with the highest number of cases is Surabaya city with 276 cases. Meanwhile, Mojokerto and Batu regencies have the lowest number of cases (9 cases). The average number of maternal mortality is 14.05 cases with Surabaya having the highest number of cases (37 cases) and the lowest is in Mojokerto and Madiun regencies with only one case.

\section{B. Bivariate Generalized Poisson Regression Distribution Test}

In BGPR and GWBGPR modeling, it is assumed that the response variable used follows the Bivariate Generalized Poisson distribution.

$\mathrm{H}_{0}$ : $\mathrm{Y}_{1}$ and $\mathrm{Y}_{2}$ (response variables) follow the Bivariate Generalized Poisson distribution.

$\mathrm{H}_{1}$ : $\mathrm{Y}_{1}$ and $\mathrm{Y}_{2}$ (response variables) do not follow the Bivariate Generalized Poisson distribution.

By using Croxkett's test, the statistical value obtained is 1.0209 .

The value of $T$ is smaller than $\chi_{(38 ; 0.05)}^{2}=53.384$ thus the decision to fully reject $\mathrm{H}_{0}$ is taken. In conclusion, the variables of infant and maternal mortality follow the Bivariate Generalized Poisson distribution.

\section{Correlation Test between Variables and Multicollinearity}

The correlation coefficient between response variables may indicate whether the number of infant mortality has a correlation with the number of maternal mortality or not. The hypothesis for the Correlation Test between response variables are stated as follows:

$\mathrm{H}_{0}$ : There is no correlation between $\mathrm{Y}_{1}$ and $\mathrm{Y}_{2}$

$\mathrm{H}_{1}$ : There is a correlation between $\mathrm{Y}_{1}$ and $\mathrm{Y}_{2}$

The test statistic used in this test is expressed as follows:

$$
t=\frac{0.782 \sqrt{38-2}}{\sqrt{1-(0.782)^{2}}}=7.528
$$

The value $t$ obtained is 7.528 , which is greater than $t_{(0.025 ; 36)}=2.028$. Therefore, there is a significant relationship between the infant and maternal mortality cases. The criteria that can be used to detect the presence of multicollinearity cases is VIF value. If the VIF value is greater than 10, the multicollinearity case exists. The VIF values of the predictor variables in this research are shown in Table 3.

TABLE 3

VIF VALUES OF PREDICTOR VARIABLES

\begin{tabular}{ccccccc}
\hline \hline Variables & $\mathrm{X} 1$ & $\mathrm{X} 2$ & $\mathrm{X} 3$ & $\mathrm{X} 4$ & $\mathrm{X} 5$ & $\mathrm{X} 6$ \\
\hline $\mathrm{VIF}$ & 2.617 & 1.937 & 1.515 & 2.123 & 1.533 & 2.409 \\
\hline \hline
\end{tabular}

Table 3 shows that all predictor variables have VIF values lower than 10 , thus the predictor variables are not mutually correlated. In conclusion, there are no multicollinearity cases in the predictor variables used. Therefore, all predictor variables can be used for further analysis of BGPR and GWBGPR modeling.

\section{Infant and Maternal Mortality Modeling with Bivariate Generalized Poisson Regression}

A concurrent testing is needed to determine at least one used variable which will affect the model formed with the following hypothesis as stated below.
$\mathrm{H}_{0}: \beta_{j 1}=\beta_{j 2}=\ldots=\beta_{j 6}=0 ; j=1,2$ and $\alpha_{1}=\alpha_{2}=0$

$\mathrm{H}_{1}$ : there are at least one $\beta_{j 6} \neq 0$ and $\alpha_{j} \neq 0$

The deviants value obtained is 7813,158 . Comparison between deviants value and the value of $\chi_{(0,05 ; 12)}^{2}$ is 21.026 . To conclude, $\mathrm{H}_{0}$ is rejected because of $D(\hat{\beta})>\chi_{(0,05 ; 15-3)}^{2}$. It shows that the predictor variables used simultaneously have a significant effect on the model. BGPR modeling for the infant and maternal mortality cases is expressed as follows:

$\hat{\lambda}_{1}=\exp \left(1.835-0.004 X_{1}-0.019 X_{2}+0.005 X_{3}+0.011 X_{4}+0.001 X_{5}+0.018 X_{6}\right)$ $\hat{\lambda}_{2}=\exp \left(0.281-0.022 X_{1}-0.011 X_{2}+0.005 X_{3}-0.013 X_{4}+0.025 X_{5}+0.031 X_{6}\right)$

The variables that significantly influence the number of infant mortality with a significant level being used is $5 \%$ are pregnant women visit health workers at least 4 times during pregnancy, pregnant women received $\mathrm{Fe} 3$ tablets, obstetric complication handled, confinement service by health personnel, and clean and healthy households. Whereas, there are five variables that significantly affect the number of maternal mortality. The variables are the percentage of pregnant women visit health workers at least 4 times during pregnancy, pregnant women received $\mathrm{Fe} 3$ tablet, obstetric complications handled, clean and healthy households, and married women with the first marriage age under the age of 18 years. AIC obtained from BGPR modeling is 5,682.156.

\section{E. Spatial heterogeneity test}

The diversity of regional's characteristics for the number of infant and maternal mortality data as well as variables that affect it can be identified through spatial heterogeneity testing with the following hypothesis:

$\mathrm{H}_{0}: \sum_{1}=\sum_{2}=\ldots=\sum_{n}=\sum$ (there is no spatial heterogeneity)

$\mathrm{H}_{1}$ : there is at least one $\sum_{n} \neq \sum$ (there is a spatial heterogeneity)

The $G$ and $\chi_{(0,05 ; 12)}^{2}$ value obtained are 24.736 and 21.026 respectively. Thus, $\mathrm{H}_{0}$ is rejected due to $G>\chi_{(0,05 ; 12)}^{2}$ which means that the number of infant and maternal mortality have spatial diversity among regions in East Java.

\section{F. Infant and Maternal Mortality Modeling with GWBGPR}

A concurrent testing is needed to determine at least one used variable which will affect the model formed with the following hypothesis as stated below.

$\mathrm{H}_{0}: \beta_{j 1}\left(u_{i}, v_{i}\right)=\beta_{j 2}\left(u_{i}, v_{i}\right)=\ldots=\beta_{j k}\left(u_{i}, v_{i}\right)=0$ and

$$
\alpha_{1}\left(u_{i}, v_{i}\right)=\alpha_{2}\left(u_{i}, v_{i}\right)
$$

$\mathrm{H}_{1}$ : there are at least one $\beta_{j k}\left(u_{i}, v_{i}\right) \neq 0$ and $\alpha_{j}\left(u_{i}, v_{i}\right) \neq 0$

The deviants value obtained is 123,342.61. Comparison between deviants value and the value of $\chi_{(0,05 ; 12)}^{2}$ is 21.026 . To conclude, $\mathrm{H}_{0}$ is rejected because $D(\hat{\beta})>\chi_{(0,05 ; 15-3)}^{2}$. It shows that the predictor variables used simultaneously have a significant effect on the model. By using adaptive bi-square kernel weighting, it generates 3 region groups on the number of infant mortality and 5 region groups on maternal mortality cases. Region grouping based on infant and maternal mortality modeling are illustrated in Fig. 1 and 2. 


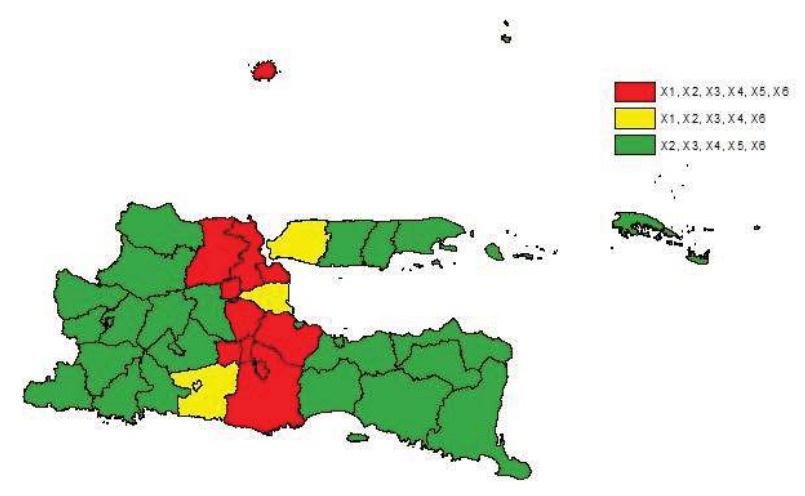

Fig. 1 Map of Region Grouping for Number of Infant Mortality

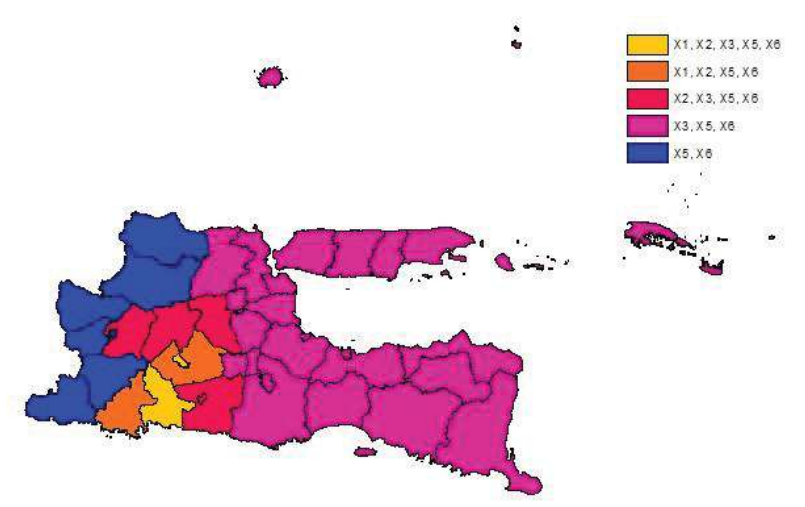

Fig. 2 Map of Region Grouping for Number of Maternal Mortality

Furthermore, region grouping is done for variables that significantly affect the number of infant mortality.

A parameter testing result in Jombang regency has an AIC value of $2,848.392$. The model is stated as follows:

- The Number of Infant Mortality

$\hat{\lambda}_{2}=\exp \left(0.676-0.011 X_{1}-0.003 X_{2}+0.008 X_{3}+0.049 X_{4}-0.001 X_{5}+0.003 X_{6}\right)$

In each addition of $1 \%$ of pregnant women health workers at least 4 times during pregnancy, the average number of infant mortality will decrease by 0.989 times with the assumption that other variables are constant. If living clean and healthy households in Jombang increased by $1 \%$, the number of infant mortality will decrease the number of infant mortality by 0.999 times and the increase of $1 \%$ of married women with first marriage age under 18 years will increase the number of infant mortality by 1.003 times. Every $1 \%$ of obstetric complications handled and delivery assisted by health personnel will each increase the number of infant mortality by 1.008 and 1.050 times. Variable obstetric complications are handled and delivery assisted by health personnel has a non-conformity in the direction of the relationship in the model of infant mortality. This is due to the dependency between the predictor variables or the data retrieval process. The data used is the total data for one year, where the development of the size of each variable is not always constant in one year and not necessarily represent the condition every month. The changed signs are caused by the correlation between obstetric complication variables handled and delivery assisted by health personnel to the number of infant mortality indicating a positive correlation pattern and this is not in accordance with the fact that should have a negative correlation pattern.
- Number of Maternal Mortality

$\hat{\lambda}_{1}=\exp \left(0.281+0.010 X_{1}-0.012 X_{2}+0.005 X_{3}+0.006 X_{4}+0.019 X_{5}+0.025 X_{6}\right)$ Each addition of $1 \%$ of pregnant women who get $\mathrm{Fe} 3$ tablets will decrease the number of maternal mortality by 0.988 times with the assumption that other variables are constant. If a married woman with a first marriage age under the age of 18 increase $1 \%$, the number of maternal mortality will increase by 1.025 each with the assumption that other variables are constant. The addition of $1 \%$ of obstetric complications handled and living clean and healthy households will increase the number of maternal deaths by 1.005 and 1.019 times. The variables of obstetric complications handled and living clean and healthy households have a mismatched relationship in the model of infant mortality caused by dependencies between the predictor variables or the data retrieval process. The correlation pattern between obstetric complications handled and living clean and healthy households on the number of maternal mortality is not in accordance with reality. The pattern of correlation between the two variables on the number of maternal mortality has a positive pattern but in fact, the pattern should be a negative correlation and this is causing the change of sign.

\section{G. Selection of the Best Model}

The MSE criteria are used to evaluate the performance of predictors or estimators. MSE is also used to convey the concept of bias, precision, and accuracy in statistical estimation. The MSE calculations for regression models with multivariate responses are as follows

TABLE 4

MSE'S VALUES

\begin{tabular}{ccc}
\hline \hline & BGPR & GWBGPR \\
\hline Number of Infant Mortality & 5974 & 5678,236 \\
Number of Maternal Mortality & 63,368 & 53,631 \\
\hline Total & 6037,368 & 5731,868 \\
\hline \hline
\end{tabular}

Table 4 shows the MSE values of each modeling method. Based on these results, the smallest MSE values were obtained from the GWBGPR model to model the number of infant mortality and the number of maternal mortality.

\section{V.CONCLUSION}

The conclusion obtained from Geographically Weighted Bivariate Generalized Poisson Regression modeling using Adaptive Bisquare Kernel weighing produces 3 districts groups on infant mortality and 5 districts groups on the number of maternal mortality. Variables that significantly affect the number of infant and maternal mortality are the percentages of pregnant women visit health workers at least 4 times during pregnancy, pregnant women receiving $\mathrm{Fe} 3$ tablets, obstetric complications treated, living clean and healthy households, and married women of the first marriage age under 18 years of age. Based on these results it can be seen that the smallest MSE values are obtained from the GWBGPR model. 


\section{REFERENCES}

[1] N. F. Rachmah, " Pemodelan Jumlah Kematian Ibu dan Jumlah Kematian Bayi di Provinsi Jawa Timur Menggunakan Bivariate Poisson Regression," Jurnal Sains dan Seni ITS, vol. 3, 2014.

[2] I. Arkandi, "Analisis Faktor Risiko kematian Ibu dan Kematian Bayi dengan Pendekatan Regresi Poisson Bivariat di Provinsi Jawa Timur Tahun 2013," Jurnal Sains dan Seni ITS, vol. 4, 2015.

[3] N. Ismail and A. A. Jemain, " Generalized Poisson Regression : An Alternative for Risk Classification.," Jurnal Teknologi, vol. 1, no. 43, pp. 39-54, 2012.

[4] D. I. Setiawan, "Penaksir Parameter dan Pengujian Hipotesis pada Geographically Weighted Bivariate Generalized Poisson Regression (Studi Kasus: Jumlah Kematian Bayi dan Kematian Ibu di Provinsi Jawa Timur Tahun 2013)," Surabaya, 2017.

[5] R. Myers, Classical and Modern Regression with Applications (Second Edition ed.), Boston: PWS-KENT Publishing Company, 1990.

[6] R. Jhonson and D. Wichern, Applied Multivariate Statistical Analysis, vol. 5, NJ: Prentice Hall, 2007.

[7] A. Fotheringham, C. Brunsdon and M. Charlton, Geographically Weighted Regression, UK: Jhon Wiley \& Sons, 2002.

[8] T. Nakaya, A. Fotheringham, C. Brunsdon and M. Charlton, "Geographically Weighted Poisson Regression for Disease Association Mapping," Statistic in Medicine, vol. 24, no. 17, 2005.

[9] D. Gujarati, Basic Econometrics, 4th ed., New York: The McGraw company Hill, 2004.

[10] BAPPENAS, Faktor-Faktor yang Mempengaruhi Kelangsungan Hidup Anak., Jakarta: Kedeputian Evaluasi Kinerja Pembangunan BAPPENAS [, 2009.

[11] Kemenkes, Profil Kesehatan Indonesia 2016, Jakarta: Kemenkes RI, 2017.

[12] Depkes, Profil Kesehatan Jawa Timur 2016, Surabaya: Dinas Kesehatan Provinsi Jawa TImur, 2017. 